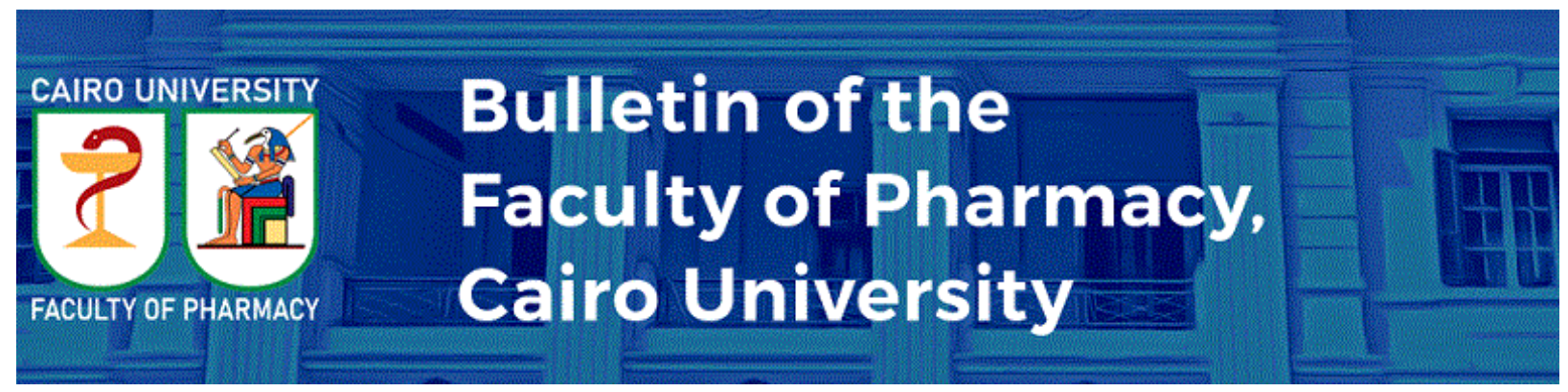

Volume 59

Issue 1 Vol 59 Issue 1 - 2

Article 1

\title{
The Use of Natural Polymers in Formation of Polyelectrolyte Complexation
}

Niharika Lal

Department of Pharmacy, IEC Group of Institutions, Greater Noida, Uttar Pradesh, India

Athira Nair

Department of Pharmacy, IEC Group of Institutions, Greater Noida, Uttar Pradesh, India

Navneet Verma

Department of Pharmacy, IFTM University, Moradabad, Uttar Pradesh, India

Follow this and additional works at: https://www.bfopcu.eg.net/journal

Part of the Pharmaceutics and Drug Design Commons

c) (i) $\odot$

This work is licensed under a Creative Commons Attribution-NonCommercial-No Derivative Works 4.0 International License.

\section{Recommended Citation}

Lal, Niharika; Nair, Athira; and Verma, Navneet (2021) "The Use of Natural Polymers in Formation of Polyelectrolyte Complexation," Bulletin of Faculty of Pharmacy Cairo University: Vol. 59 : Iss. 1 , Article 1.

Available at: https://doi.org/10.54634/2090-9101.1020

The Review Article is brought to you for free and open access by Bulletin of the Faculty of Pharmacy Cairo University. It has been accepted for inclusion in Bulletin of Faculty of Pharmacy Cairo University by an authorized editor of Bulletin of the Faculty of Pharmacy Cairo University. 


\title{
The Use of Natural Polymers in Formation of Polyelectrolyte Complexation
}

\author{
Niharika Lal ${ }^{\mathrm{a}, *}$, Athira Nair ${ }^{\mathrm{a}}$, Navneet Verma ${ }^{\mathrm{b}}$ \\ ${ }^{a}$ Department of Pharmacy, IEC Group of Institutions, Greater Noida, Uttar Pradesh, India \\ ${ }^{\mathrm{b}}$ Department of Pharmacy, IFTM University, Moradabad, Uttar Pradesh, India
}

\begin{abstract}
In recent years, great advances have been made towards the development of various techniques for novel drug delivery systems. These techniques focus on the rate of drug delivery, duration of action and site of action. One of such technique in fabricating novel drug delivery system is the use of polymers in development of in-situ drug delivery systems. Polymers used as carriers have revolutionized over the years. The formation of a polymer complex with other oppositely charged polymers resulted in the formation of polyelectrolyte complexes, which possess unique physicochemical properties with high biocompatibility. The polyelectrolyte's themselves are characterized as cationic, anionic and non-ionic according to the nature of the functional group present at the polymer chain, type of macromolecules formed and interaction forces existing between the complex formed. Additionally, these natural complexes avoid the use of chemical agents for cross linking of polymeric chains, thereby limiting toxicity. Due to their sustain and convenient way to deliver highly water soluble drugs they could target therapeutically active moiety to the site of action, and for these reasons they have led to various applications in the biomedical sector, in pharmaceutical and nano biotechnology industries. Thereby the use of polymers in in-situ drug delivery offers many benefits because of their sustained and prolonged drug delivery action when compared with other conventional drug delivery systems. The present review focuses on the use of natural Polymers in polyelectrolyte complexes as a drug delivery technology.
\end{abstract}

Keywords: Sustained release, Natural polymers, Polyelectrolyte, Drug delivery technology

\section{Introduction}

$\mathrm{V}$ arious new approaches and advancements have been made in novel drug delivery systems. The new approaches implemented so far focuses on better and highly novel techniques for targeting drugs at specific site of action [1].

One such advancement is the use of polymers as drug carriers especially in in-situ drug delivery systems. The complex forms between oppositely charged polymeric material results in formation of polyelectrolyte complexes. The polymer is known to play an active role in sustained and controlled release of the drug. Since different polymers possess different physicochemical properties, they are usually incorporated as coating material, film forming agent, drug carrier, granulating agent, excipient in tablet formation and as solubilising agents. The role of polymers in drug delivery accelerates by undergoing phase transition in response to an external stimulus such as change in temperature, electric potential, $\mathrm{pH}$ and ionic strength.

This systems are considered to play a vital role for achieving sustained release of drug due to their favourable properties of water solubility, biodegradability, biocompatibility, non-toxicity [2].

The polyelectrolyte complexes (PEC) are formed due to the electrostatic interaction between the opposite charged polymers/poly-ions. Such interaction limits toxicity as well as undesirable side effects. Priory this charge to charge interaction between ionic polymers and drugs were not considered to be useful, but now due to the

Received 22 January 2021; revised 10 March 2021; accepted 16 March 2021

Available online 30 December 2021.

* Corresponding author.

E-mail address: niharikalal24@gmail.com (N. Lal). 
advancement in research and exploitation of these interactions they are considered to be very useful and give highly successful results in all of the new approaches developed so far [3].

With the development of in-situ polymeric drug delivery systems, it has enhanced the ease of administration of drugs, limited dose frequency as well as improved patient compliance. As such, various cationic and anionic polymers have been used so far in the development of in-situ drug delivery systems. Depending upon the route of administration these systems have been classified into the following parts:

a) In-situ forming polymeric systems for oral administration.

b) In- situ forming polymeric systems for ocular delivery.

c) In-situ forming injectable drug delivery system.

d) In-situ forming polymeric systems for rectal and vaginal delivery.

e) In-situ forming nasal drug delivery system.

\subsection{Polyelectrolytes}

The polyelectrolytes are polymers that contain a negative and a positive charge at neutral $\mathrm{pH}$ [4]. They are formed by strong electrostatic interactions between oppositely charged polyelectrolyte's, leading to inter polymer ionic condensation as well as release of counter ions simultaneously. These Polyelectrolyte complex (PEC) tend to combine the physicochemical properties of at-least two of the polyelectrolyte's being used. And they easily get dissociated in water as well as they are considered to be highly soluble due to the electrostatic interaction between the polymer and the charged monomers [5].

\subsection{Classification of polyelectrolytes}

The polyelectrolyte's are considered to be both organic as well as inorganic, as they exhibit both the properties such as flocculation and de-flocculation. The coagulants exhibiting sedimentation property in low molecular weight synthetic polymers are considered as inorganic polyelectrolyte's. While the ones exhibiting this property in high molecular weight synthetic polymers are considered as organic polyelectrolyte's (Table 1).

The classification is as follows:

a) Based on the origin:

1) Synthetic polyelectrolytes - poly (styrene sulfonic acid), poly (acryl alkyl trialkyl
Table 1. Natural polymers in formation of polyelectrolyte complex.

\begin{tabular}{ll}
\hline Name & $\begin{array}{l}\text { Category } \\
\text { (based on the } \\
\text { charge type) }\end{array}$ \\
\hline Natural polyelectrolytes & Polyanion \\
Nuclei acids & $\begin{array}{l}\text { Polycation } \\
\text { Poly (L-lysine) }\end{array}$ \\
Poly (L-glutamic acid) & $\begin{array}{l}\text { Polyanion } \\
\text { Polyanion }\end{array}$ \\
Carageenan & Polyanion \\
Alginates & polyanion \\
Hyaluronic acid & \\
Pectin & Polyanion \\
Chitosan (deacetylation of chitin) & Polycation \\
Cellulose-based & Polyanion or \\
Starch-based & Polycation \\
Dextran-based & Polyanion or \\
& Polycation \\
Synthetic polyelectrolytes & Polyanion or \\
Poly (vinylbenzyl trialkyl ammonium) & Polycation \\
Poly (4-vinyl-N-alkyl-pyridimiun) & Polycation \\
Poly (acryloyl-oxyalkyl-trialkyl ammonium) & Polycation \\
Poly (acryamidoalkyl-trialkyl ammonium) & Polycation \\
Poly (diallydimethyl-ammonium) & Polycation \\
Poly (styetenesulfonic acid) & Polycation \\
Poly (vinylsulfonic acid) & Polyanion \\
Poly (acrylic or methacrylic acid) & Polyanion \\
Poly (itaconic acid) & Polyanion \\
Maleic acid/diallyamine copolymer & Polyanion \\
& Poly-ampholytic \\
\hline &
\end{tabular}

ammonium), poly (vinyl benzene tri alkyl ammonium), poly (vinyl sulfonic acid), poly (acrylic or methacrylic acid).

2) Chemically modified polymers - Pectin, chitin, cellulose based, dextran based.

3) Natural polyelectrolytes - Nucleic acids, carrageenan, alginates.

b) Based on charge:

1) Anionic (negatively charged) - When the charge carried by active portion of the polymer is negative it is termed as anionic. These are produced by ionisation of acrylic acid unit of a polymer. Examples are Polyacrylamides (homo/ co polymers of $\mathrm{Na}$ salt of acrylic acids with acrylamide).

2) Cationic (positively charged) - When the charge carried by active portion of the polymer is positive it is termed as cationic. Here, the nitrogen parts of the polymer posses the positive charge. They are available in wide range depending upon the cationic monomer present, the charge density and the molecular weight. Examples are homo/co polymers with acrylamide of three major cationic monomers.

3) Non-ionic (no charge) - When no charge is present on the active portion of the polymer it is 
termed as non-ionic. Examples are, large homopolymers of acrylamide with wide range of molecular weights $[6,7]$.

\subsection{Mechanism of formation of PEC'S}

The PEC's are obtained by three step process -

1) Primary complex formation

2) Formation within intra-complexes

3) Intra-complex aggregation

\subsubsection{Primary complex formation}

This is the $1^{\text {st }}$ step towards the formation of PEC's which is governed by coulombs forces. It is a rapid process where the mixing between oppositely charged polyelectrolyte's takes place.

\subsubsection{Formation within intra-complexes}

This second step towards the formation of PEC's is the formation of intra-complexes which proceeds after half an hour from the initial first step. New bonds are formed and distorted polymeric chains are modified.

\subsubsection{Intra-complex aggregation}

This is the final step towards the formation of PEC's in which the intra-complexes formed in the $2^{\text {nd }}$ step, undergoes aggregation via hydrophobic interactions. These are insoluble in ordinary solvents and the molar ratio is almost unity (Fig. 1) [8].

\section{Structural models of PEC's}

There are three different types of structures that are formed during polycation-polyanion interaction.

i) Water soluble

ii) Colloidal stable

iii) Two phase system

\subsection{Water soluble}

The water-soluble aggregates formed consist of long host molecules complexes in an orderly manner with shorter poly-ions of opposite charge. These are formed when polyelectrolytes with weak ionic groups and large differences in molar mass are mixed in a non-stoichiometric ratio. (The ratio between cationic and anionic groups must be $>1$ or $<1$ but not $=1$ ). Their stability is affected by concentration of soluble salts and ratio of charge between the two polyelectrolyte's [9].

\subsection{Colloidal stable}

The colloidal stable PEC's can be obtained by inhibiting the formation of water-soluble PEC's

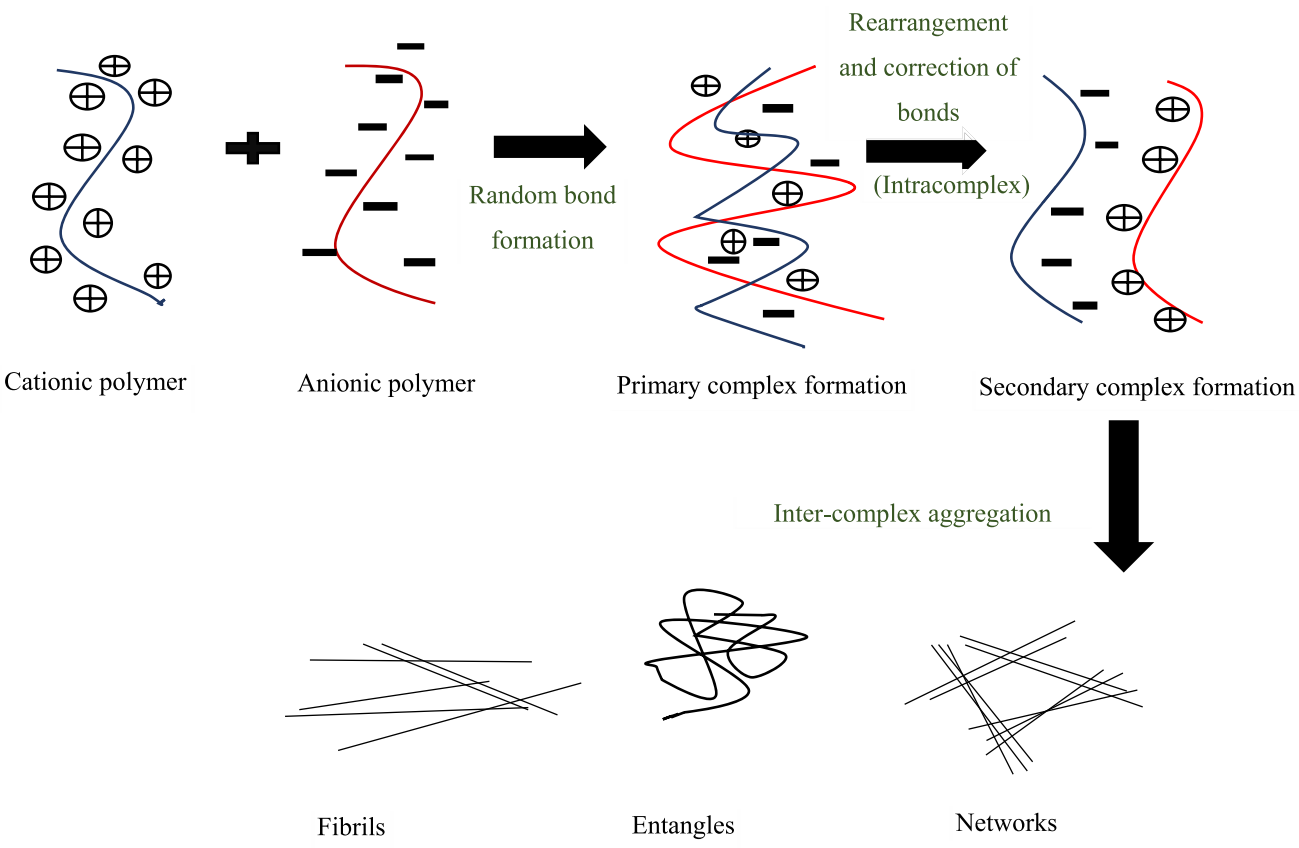

Fig. 1. Schematic Representation of mechanism of formation of polyelectrolytes. 
which results in highly aggregated and macroscopically heterogeneous system due to complex formation between high or moderately high molecular weight polyelectrolyte's. This can be inhibited by using extremely diluted solution of a low or moderate ionic strengths at non-stoichiometric conditions [10].

\subsection{Two phase system}

The two phase system comprises of a liquid phase and a PEC's rich phase which can be obtained by mixing highly concentrated solutions of high and similar molecular weight polyelectrolytes within stoichiometric ratios. The rheological properties of these electrolytes depends on the properties of polyelectrolyte's and their salt concentrations [11].

\subsection{Preparation of polyelectrolytre complexes}

For the preparation of polyelectrolyte complex solution two oppositely charged polyelectrolytes are taken and dispersed in a dispersion medium (usually deionized water) at various concentrations and at defined stoichiometric ratios. In order to get the required ionic strength, a poly salt such as sodium chloride is added and the $\mathrm{pH}$ is finally adjusted. The solutions are then filtered through $0.22 \mu$ Millipore membrane [12,13].

\subsubsection{PEC formation and particle refinement}

The PEC's are either polycation or polyanion prepared at room temperature. The complex formation process is done by the slow addition of polyanionic solution (dropwise) at a controlled rate to a polycationic solution of same strength [14]. It can also be done by constant magnetic stirring with one-shot addition of one of the polyelectrolyte solution to the oppositely charged polyelectrolyte solution possessing the same ionic strength [15]. In case of particle refinement, this process is carried out through centrifugation process, but it is important to avoid physiosorption of the free polymers onto the surface of already formed PEC's. The final product is usually suspended in a minimum volume of deionised water [16,17].

\subsection{Factors affecting polyelectrolyte complexes}

While mixing two oppositely charged polyelectrolytes it causes separation of polymer richphase (milky phase) from Polymer depleted-phase (clear phase) (Table 2) [18,19].

\section{a) Structure parameters}

\section{- Charge-to-charge stoichiometry}

It is the ratio of positive to negative charge of the oppositely charged polyelectrolytes involved in the formation of PEC's and is denoted as $\mathrm{Z}$ with subscripts $(+I-$ or $-I+)$. Their stoichiometry is denoted by $\Phi$ [20]. The polyelectrolytes formed are considered to be hydrophobic and precipitate from the aqueous solution when Stochiometric-PEC's $(\Phi=1)$, while if Non Stochiometric -PEC's $(\Phi=1)$ then it results in overcharging effect due to the presence of either excess of polycation or polyanion [21-23].

\section{- Charge density}

This parameter was explained using cationic and anionic copolymers of acrylamide by Dautzenberg et al., (1997). They observed that when equal charge density is present on the polyelectrolytes it forms a compact structure while if the system contain strong deviating charge density then it results in loose fluctuating structure [24].

\section{- Molecular weight}

The molecular weight of the polyelectrolyte is directly proportional to its particle size. If the molecular weight of polyelectrolytes is increased it results in an increased particle size. Therefore larger the chain more likely the positively charged electrolytes will complex with negatively charged ones [25].

\section{b) Media parameters}

- Polyelectrolyte concentration

The concentration of polyelectrolytes is directly proportional to the particle size and inversely

Table 2. Illustrative representation of various factors affecting the formation of PEC's.

\begin{tabular}{lll}
\hline Structural parameters & Media parameters & Preparation parameters \\
\hline$\bullet$ Charge- to- charge stoichiometry & $\bullet$ Polyelectrolyte concentration & $\bullet$ Mode of mixing of polyelectrolytes \\
$\bullet$ Charge density & $\bullet$ pH of reaction medium & $\bullet$ Order of mixing of polyelectrolytes \\
$\bullet$ Molecular weight of polyelectrolytes & $\bullet$ Salt concentration & $\bullet$ Mixing ratio \\
& & $\bullet$ Duration of interaction \\
\hline
\end{tabular}


proportional to electrostatic repulsion occurring between them. The dispersive interaction between polyelectrolytes could be elevated by increasing the concentration of the polyelectrolytes which reduces the electrostatic repulsion between them and results in increment of particle size per volume [26].

- The $\mathrm{pH}$

The $\mathrm{pH}$ plays a role in particle size and the nature of coagulation. It is directly proportional to the size of the particles and if value of $\mathrm{pH}$ is decreased it would resulted to decreased particle size. While considering charged particles, if PEC's comprise of highly charged particles with lower $\mathrm{pH}$ values they will show lesser amount of coagulation due to mutual electrostatic repulsion, whereas if they possess low charged particles having high $\mathrm{pH}$ level they will show coagulation due to electrostatic attraction existing between them [27].

\section{- Salt concentration}

The effect of salt concentration on the properties of PEC's can be studied either during complexation or after complexation. It has been observed that the particle size of PEC's considerably increases on increasing the salt concentration and even favours coagulation [28].

\section{- Ionic strength}

The ionic strength of polyelectrolyte's is inversely proportional to its size. So with an increase in ionic size it decreases the average size and thereby induces an increase in chain flexibility.

\section{c) Preparation parameters}

- Mode of mixing of polyelectrolyte solutions

The mixing of polycation and polyanion for the preparation of polyelectrolytes depends on factors such as the kind of mixing done, the mixing protocol and the type of device used. For low molecular weight polyelectrolytes smaller PEC's are obtained at shorter mixing times whereas in case of polyelectrolytes with high molecular weight the size of PEC's are decreased initially with shorter mixing time and then increased by increasing the mixing time $[12,28]$.

\section{- Order of addition}

The order of addition of polyelectrolytes is considered to be an important parameter as the polymer existing as default must be added in excess to avoid aggregation. The rapid one-shot mixing procedure is considered beneficial over the slow dropwise mixing as the former gives PEC's of smaller diameter and high stability [28].

\section{- Mixing ratio}

The mixing ratio is inversely proportional to particle size and molecular weight. When the mixing ratio is increased in a saltless system it causes a decrease in the molecular weight as well as decrease in the particle size of the PEC's. Some studies showed that in case of a salted system, due to the presence of salts, there is a considerable increase in the particle size and decrease in the amount of aggregation between the particles [29].

\subsection{The use of polymers in in-situ polymeric drug delivery system}

This system offers sustained and controlled release of the drug with a better therapeutic outcome. The in situ polymeric formulation used in drug delivery is basically present in solution form before being administered into the body. Upon administration, it undergoes gelation to form gel. There are various factors which affect the formation of gel these include $\mathrm{pH}$ change, temperature modulation, ultra-violet irradiation and presence of ions. The polymers used for this purpose include gellan gum, alginic gum, xyloglucan, pectin, chitosan, poly (DL-lactic acid), poly (DL-lactide-co-glycolide and poly-caprolactone. The choice of solvent to be used depends on the nature of solubility of the polymer being used. These preparations formed can be used in oral, rectal, vaginal, injectable and intraperitoneal routes $[30,31]$.

\section{A) In situ oral drug delivery system}

In oral drug delivery system pectin, xyloglucan and gellan gum are the natural polymers used for in situ polymeric drug delivery system. The pectin is a natural anionic polymer used in in situ oral drug delivery system. The polymer backbone comprises of $\alpha$-(1-4)-D-galacturonic acid. The polymer readily forms gel in aqueous solution in the presence of calcium since the calcium ions present in the formulation form a crosslink with galacturonic acid chain in an egg-box model. Similarly sodium citrate can be added to pectin to form a complex with the calcium ions present in the formulation, this allows the formulation to be in a fluid state (sol) on administration, until the complex is broken down when it comes in contact with the acidic 
environment of the stomach, where the release of calcium ions initiates gelation. Since it is water soluble and no other organic solvents are required for the formulation it is therefore considered as an ideal system for sustained drug delivery. Example, Paracetamol has been formulated as in situ gelling pectin [32].

Kwasaki $\mathrm{N}$ et al., studied on xyloglucan as a vehicle for oral drug delivery system. Xyloglucan is natural non-ionic polymer, It is a polysaccharide obtained from tamarind seeds and comprises of (1-4)- $\beta$-D-glucan as backbone chain which consist of (1-6)- $\alpha$-D xylose branches partially substituted by (1-2)- $\beta$-D-galactoxylose [33]. This polymer undergoes thermally reversible gelation when it is partially degraded by $\beta$-galactosidase through the lateral stacking of the rod like chains. It forms gel at much lower concentration since the solution to gel transition depends on the degree of galactose eliminated. Apart from its use in oral drug delivery it has been found useful in ocular, intraperitoneal and rectal drug delivery systems $[34,35]$.

Gellan gum it is an anionic deacetylated exocellular polysaccharide secreted by Pseudomonas elodea consisting tetra-saccharide repeating unit of one $\alpha$-L-rhamnose, one $\beta$-D-glucuronic acid and two $\beta$-D-glucuronic acid [36,37]. This polymer undergoes gelation which is temperature and cations mediated. The gelation results in a double helical junction zone followed by aggregation of the double helical segment to form three-dimensional network by complexing with cations and forming hydrogen bonds with water [38-40]. Example: It has been used as a vehicle for oral drug delivery of theophylline in which the formulation comprises of gellan solution complexed with calcium chloride and sodium citrate [41,42]. During oral administration the calcium ions get released in the acidic environment of the stomach causing gelation $[43,44]$.

\section{B) In situ ocular drug delivery system}

The in situ based ocular drug delivery is carried out using natural polymers such as gellan gum, alginic acid, and xyloglucan. This method has been considered beneficial and more sufficient than other conventional drug delivery system and is often been used for the delivery of antimicrobial agents, antiinflammatory agents and autonomic drugs for the treatment of glaucoma [45].

The aqueous solution of Gellan gum has been used here for release of the medication into the eye, upon administration due to temperature difference as well as the ionic condition of the tissue fluid the solution phase is converted to gel phase [46,47].
Alginic acid is an anionic linear block copolymer polysaccharide comprising of $\beta$-D-mannuronic acid and $\alpha$-L-glucuronic acid residues attached to $1,4-$ glycosdic linkage. The arrangement within the molecules vary depending on the algal source. This polymer undergoes gelation on addition of di-and trivalent metal ions through a process involving formation of glucuronic residues from the $\alpha$-L-glucuronic acid of the alginate chain. It has been considered as a vehicle for ophthalmic formulations, as it exhibits properties such as biodegradability, mucoadhesive character and non-toxicity [48].

Carbopol is a $\mathrm{pH}$ dependent polymer. At acidic $\mathrm{pH}$ it stays in solution form while in alkaline $\mathrm{pH}$ it forms a gel $[49,50]$. Hydroxy-propyl-methylcellulose is often used in combination with Carbopol, this is because here it aids the Carbopol by reducing the acidity of the system thus imparting viscosity which is enough to induce sufficient alkalinity to change in gel form. Example: Indomethacin for the treatment of uveitis has been formulated by this concept. Sustained release of the drug for a period of 8 hours in vitro was observed and considered better than other conventional methods [51,52].

Miyazaki et al., conducted studies on rabbit eye and formulated in situ gels for the ocular delivery of pilocarpine hydrochloride using xyloglucan as the polymer and it showed a significant mitotic response for a period of 4 hours when instilled into the lower cul-de-sac portion of rabbit eye [53].

\section{C) In situ vaginal and reactal drug delivery system}

Various in situ gel formulations have been developed for drug delivery though vaginal and rectal route. Miyazaki et al., studied the rectal drug delivery of indomethacin with the use of xyloglucan based thermo-reversible gels. This formulation was subjected to rabbits and it showed a higher drug absorbance peak. Significant decrease in $C_{\max }$ and a longer residence time of the drug with the ability of being non-toxic to the nervous system [54].

Bilensoy $\mathrm{E}$ et al., proposed a study for prolonging the treatment of vaginitis where he prepared vaginal gel comprising clotrimazole-beta-cyclodextrin complexed with pluronic F-127 in situ polymer along with Carbopol and hydroxy-methylcellulose, which showed longer residence time of the drug thus improving its therapeutic efficacy [55].

\section{D) In situ injectable drug delivery system}

Various polymers are being used with the development of in-situ polymeric drug delivery system. Chitosan is one such cationic polymer that is being 
Table 3. List of Studies illustrating the sustained release of drugs through in situ gels.

\begin{tabular}{|c|c|c|c|}
\hline Drug & Polymer used & $\begin{array}{l}\text { Route of } \\
\text { administration }\end{array}$ & Results \\
\hline Doxorubicin [29] & $\begin{array}{l}\text { Human serum albumin } \\
\text { and tartaric acid derivative }\end{array}$ & Injectable & $\begin{array}{l}\text { Sustained delivery of anticancer drug for a prolonged } \\
\text { period of time } 0.100 \text { hours }\end{array}$ \\
\hline Proteins [30] & Poly lactide-c-glycolide & Injectable & Controlled release of proteins. \\
\hline Testosterone [31] & Poly-lactic acid and PLGA & Injectable & A controlled zero order in-vitro release was observed. \\
\hline $\begin{array}{l}\text { Phenaramine maleate and } \\
\text { albumin FTIC [32] }\end{array}$ & $\begin{array}{l}\text { Polyacrylic acid and } \\
\text { polymethacrylic acid }\end{array}$ & Injectable & $\begin{array}{l}\text { Sustained delivery of pheniramine for } 2 \text { days and of } \\
\text { albumin-FTIC for } 5 \text { days. }\end{array}$ \\
\hline $\begin{array}{l}\text { Recombinant human } \\
\text { interleukin [31] }\end{array}$ & $\begin{array}{l}\text { Physically cross- linked } \\
\text { dextran }\end{array}$ & Injectable & $\begin{array}{l}\text { Drug loaded hydrogel releases drug over a period of } \\
5 \text { days, shows excellent biodegradability and } \\
\text { biocompatibility. }\end{array}$ \\
\hline $\begin{array}{l}\text { Paracetamol and } \\
\text { Ambroxol [32] }\end{array}$ & Pectin & Oral & Sustained oral delivery \\
\hline Theophylline [33] & Gellan gum & Oral & $\begin{array}{l}\text { Four- five fold increase of bioavailability in rats and } \\
\text { threefold increase in rabbits on comparison with } \\
\text { commercial oral formulations. }\end{array}$ \\
\hline Indomethacin [34] & Xyloglucan & Rectal & $\begin{array}{l}\text { Broad drug absorption peak and a longer residence } \\
\text { time when compared to commercial products. }\end{array}$ \\
\hline Clotrimazole [35] ${ }^{]}$ & $\begin{array}{l}\text { Pluronic F-127, } \\
\text { Carbopol 934, HPMC }\end{array}$ & Vaginal & Controlled release of drug was achieved. \\
\hline Mometasone furoate [36] & $\begin{array}{l}\text { Gellan gum and } \\
\text { xanthan gum }\end{array}$ & Nasal & $\begin{array}{l}\text { Inhibits the increase in nasal symptoms when } \\
\text { compared with commercial formulations. }\end{array}$ \\
\hline
\end{tabular}

used for this specific drug delivery system, it is a bio-degradable, thermosensitive, polycationic polymer obtained by alkaline deacetylation of chitin which is a natural component of shrimp and crab shell. This polymer usually exists as solution form at a $\mathrm{pH}$ of 6.2, on neutralization of its aqueous solution the $\mathrm{pH}$ exceeds 6.2 and it then leads to the formation of a hydrated gel-like precipitate. The polyol salts bearing a single anionic head such as glycerol, sorbitol, fructose or glucose phosphate salts are added to the chitosan aqueous solution to form a thermally sensitive $\mathrm{pH}$ dependent gel forming solution. This transformation limits its bio-degradability problem [56]. Example: This formulation has been used to deliver biologically active growth factors in vivo which turns into gel implants in situ in living chondrocytes for tissue engineering applications. Another example for studies conducted on mice for tumour treatment where a thermo-sensitive in situ gelling hydrogel consisting paclitaxel was developed which consisted chitosan solution neutralized with $\beta$-glycerophosphate. It was found to be effective as it inhibited the growth of EMT- 6 cancer cells in mice in a less toxic manner [57].

Zhang et al., developed thermoplastic plates for the local delivery of taxol from a thermoplastic triblock copolymer system composed of poly (D,Llactide)-block-poly (ethylene glycol)-block-poly (D,L-lactide) blended with low molecular weight poly (D,L-lactide) and poly (e-caprolactone) PCL. This formulation was injected in the form of solution which then got converted to form a semisolid gel mass upon cooling at body temperature. The melting points of these polymers are greater than $60^{\circ}$ because of which when administered it has the same temperature and it causes pain and chances of necrosis as well as scar at the site of injection to the patient. It therefore was not considered of much use [58].

Dardanoo et al., developed PCL as polymeric paste with a molecular weight of $10-20 \mathrm{KDa}$ to overcome the problems associated with the slow release of the above mentioned taxol. For this he used various water-soluble additives such as gelatin, albumin, methylcellulose, dextran and sodium chloride to enhance its release. These additives were mixed with taxol, pulverized and then added to molten containing low molecular weight PCL. The in vivo drug release and anti-angiogenic activity of the in-situ systems were studied using chorio-allantoic membrane. The results showed rate of swelling to be higher. Thus, the paste prepared using taxol-gelatin swelled at a faster rate and these additives increased the water imbibition thereby resulting in better dissolutions as well as drug release and this model also induced angiogenesis inhibition [59].

Sawhney et al., developed a photopolymerizable biodegradable hydrogel, as a tissue containing the drug as well as a controlled release carrier. This system comprises of a macromer (PEG-oligoglycolyl-acrylate), a photosensitive initiator (eosin dye) 
and a light source (UV or visible light). Upon exposure to light this system undergoes photopolymerization to form a network example argon laser. Further it can be employed for the release of water-soluble drugs and enzymes at a controlled rate [60].

\section{E) In situ nasal drug delivery system}

Cao $S$ et al., developed an in situ gel for mometasone furoate for the treatment of allergic rhinitis using xanthan gum and gellan gum as polymers and conducted animal studies using allergic rhinitis model and also studied the effect of in situ on antigen induced sensitized rats, which showed an effect by inhibiting the increase in nasal symptoms when compared with other marketed products. It showed the presence of normal goblet cells and an intact ciliated respiratory epithelium in rats nasal cavity which ensured its safety profile [56].

$\mathrm{Wu}$ et al., developed a new thermosensitive hydrogel for insulin using N-[(2-hydroxy-3-methyltrimethylammonium)propyl]chitosan chloride and poly (ethylene glycol) along with a small amount of alpha-beta-glycerophosphate. This solution transformed to gel at a temperature of $37^{\circ} \mathrm{C}$. The animal studies conducted showed a decline in bloodglucose level by $40-50 \%$ for about $4-5$ hours after administration without any toxicity (Table 3) [61].

\section{Conclusion}

In conclusion, the foremost requirement of any drug is to show patient compliance with effective controlled release of the drug giving an excellent therapeutic outcome, which is currently being shown with the use of in situ gels. With the advancement and diverse use of polymers including water-soluble polymers, in-situ gels could be used for the sustained release of various drugs. They are providing number of advantages over conventional dosage forms, such as better stability, biocompatibility, sustained and prolonged release of the drug. This makes it more reliable and efficient source of drug delivery system.

\section{Consent for publication}

The author provides their consent to publish this research.

\section{Funding}

No external funding was received for this study. The resources used for the study were provided by the authors.

\section{Conflict of interest}

The authors declare that there is no conflict of interests regarding the publication of this paper.

\section{Acknowledgements}

Authors are grateful to, Director, Prof. Bhanu P S Sagar of IEC Group of Institutions, for providing moral support as well as guidance for the completion of this research manuscript and Department of Pharmaceutical Technology, IEC Group of Institutions, Greater Noida, Uttar Pradesh.

\section{References}

[1] Meng S, Ting J, Hao W, Matthew T. Solid-to-Liquid phase transition in polyelectrolyte complexes. Macromolecules 2020;53(18):7944-53.

[2] Srivastava S, Adam L, David J, Matthew V. Structure, morphology, and rheology of polyelectrolyte complex hydrogels formed by self-assembly of oppositely charged triblock polyelectrolytes. Macromolecules 2020;53(14): 5763-74.

[3] Philipp B, Dautzenberg H, Linow K, Kotz J, Dawydoff W. Polyelectrolyte complexes-recent developments and open problems. Prog Polym Sci 1989;14:91-172.

[4] Syed Vaqar MS, Srivastava Samanvaya. Time-ionic strength superposition: a unified description of chain relaxation dynamics in polyelectrolyte complexes. ACS Macro Lett 2020; 9(7):1067-107.

[5] Nikolaev Konstantin G, Ulasevich Sviatlana A, Luneva Olga, Orlova Olga Yu, Vasileva Daria, Vasilev Semen, et al. Humidity-driven transparent holographic free-standing polyelectrolyte films. ACS Appl Polym Mater 2020;2(2):105-12.

[6] Kubisa P. Terminology of polymers containing ionizable or ionic groups and of polymers containing ions, IUPAC recommendations. 2004 (DRAFT 23 December 2004).

[7] Pippa N, Mountrichas G, Pispas S, Demetzos C, Sivolapenko C. Preparation and physicochemical characterization of polyelectrolyte complexes incorporating antitumor peptide. J Nanosci 2017;17(7):4901-6.

[8] Yi D, Qingqing Z, Lei W, Leilei H, Qizhou L, Xinhua L, et al. Polymerization-induced self-assembly promoted by liquid-liquid phase separation. ACS Macro Lett 2019;8(8): 943-6.

[9] Lankalapalli S, Kolapalli V. Polyelectrolyte complexes- a review of their applicability in drug delivery system Indian. J Pharmacol Sci 2009;71(5):481-7.

[10] Petzold G, Nebel A, Buchhammer H-M, Lunkwitz K. Preparation and characterization of different polyelectrolyte complexes and their application as flocculants. Colloid Polym Sci 1998;276:125-30.

[11] Zezin A, Kabanov A. A new class of complex water-soluble polyelectrolytes. Russ Chem Rev 2007;51:833-55.

[12] Delair T. Colloidal polyelectrolyte complexes of chitosan and dextran sulfate towards versatile nanocarriers of bioactive molecules. Eur J Pharm Biopharm 2011;78:10-8.

[13] Gucht J, Spruijt E, Lemmers M, Stuart MAC. Polyelectrolyte complexes: bulk phases and colloidal systems. J Colloid Interface Sci 2011;361:407-22.

[14] Abhijeet D, Yogesh H. Polyelectrolyte complexes :mechanisms,critical experimental aspects and applications. Artif Cells Nanomed Biotechnol 2016;44(7):1615-25.

[15] Pergushov V, Muller A, Schacher H. Micellar-interpolyelectrolyte complexes. Chem Soc Rev 2012;41:6888-99. 
[16] Hu Y, Yang T, Hu X. Novel polysaccharides-based nanoparticle carriers prepared by polyelectrolyte complexation for protein drug delivery. Polym Bull 2012;68:1183-99.

[17] Meng Siqi, Liu Yueming, Yeo Jihyeon, Ting Jeffrey $M$, Tirrell Matthew V. Effect of mixed solvents on polyelectrolyte complexes with salt. Colloid Polym Sci 2020; 298(7):887-94.

[18] Muller M, Kebler B, Frohlich J, Poeschla S, Torgeret B. Polyelctrolyte complex nanoparticles of poly(ethyleneimine) and poly(acrylic acid):preparation and applications. Polymers 2011;3:762-78.

[19] Mende M, Buchhammer HM, Schwarz S, Petzold G, Jaeger W. The stability of polyelectrolyte complex systems of PDADMAC with different polyanions. Macromol Symp 2004;211:121-33.

[20] Dautzenberg H. Polyelectrolyte complex formation in highly aggregating systems, Effect of salt: polyelectrolyte complex formation in the presence of $\mathrm{NaCl}$. Macromolecules 1997;30: $7810-5$.

[21] Wataru K, YasuhiroK, Miyazaki S, Attwood D. In situ gelling pectin formulations for oral sustained delivery of paracetamol. Drug Develop Ind Pharm 2004;30:593-9.

[22] Kaur K, Kaur G. Formulation and evaluation of chitosanchondroitin sulphate based nasal inserts for zolmitriptan. BioMed Res Int 2013;2013. Article ID 958465.

[23] Liu C, Xia Z, Czernuszka JT. Design and development of three-dimensional scaffolds for tissue engineering. Chem Eng Res Des 2007;85:1051-64.

[24] Luppi B, Bigucci F, Mercolini L, Musenga A, Sorrenti M, Catenacci L. Novel mucoadhesive nasal inserts based on chitosan/hyaluronate polyelectrolyte complexes for peptide and protein delivery. J Pharm Pharmacol 2009;61:151-7.

[25] Martins AF, Bueno PVA, Almeida EAMS, Rodrigues FHA, Rubira AF, Muniz EC. Characterization of N-trimethyl chitosan/alginate complexes and curcumin release. Int J Biol Macromol 2013;57:174-84.

[26] Mende M, Buchhammer HM, Schwarz S, Petzold G, Jaeger $\mathrm{W}$. The stability of polyelectrolyte complex systems of PDADMAC with different polyanions. Macromol Symp 2004;211:121-33.

[27] Chen P, Kuo T, Kuo J, Tseng Y, Wang D, Lai J, et al. Novel chitosan-pectin composite membranes with enhanced strength, hydrophilicity and controllable disintegration. Carbohydr Polym 2010;82(4):1236-44.

[28] Muller M. Sizing, shaping and pharmaceutical applications of polyelectrolyte complex nanoparticles. Adv Polym Sci 2014; 256:197-260.

[29] Tsuchida E. Formation of polyelectrolyte complexes and their structures. J Macromol Sci Pure Appl Chem 1994;31: $1-15$.

[30] Wang J, Ni C, Zhang Y, Zhang M, Li W, Yao B. Preparation and $\mathrm{pH}$ controlled release of polyelectrolyte complex of poly(1-malic acid-co-d,1-lactic acid) and chitosan. Colloids Surf B Biointerfaces 2014;115:275-9.

[31] Wu QX, Zhang QL, Lin DQ, Yao SJ. Characterization of novel lactoferrin loaded capsules prepared with polyelectrolyte complexes. Int J Pharm 2013;455:124-31.

[32] Ying JY, Wan ACA. Cell-adhesive polyelectrolyte material for use as membrane and coating. World Patent; 2007. WO 2007108775 A1.

[33] Kawaski N, Okhura R, Miyazaki S, Uno Y, Sugimoto S, Attwood D. Thermally reversible xyloglucan gels as a vehicle for oral drug delivery system. Ind Pharm 1999;181:227-34.

[34] Madan M, Bajaj A, Lewis S. Udupa N and Baig J , in situ forming polymeric drug delivery-system. Indian J Pharmaceut Sci 2009 May-Jun;71(3):242-51.

[35] Dautzenberg H, Linow KJ, Philipp B. Anionic to form watersoluble polysalts (symplexes) and cationic copolymers of acrylamide. Acta Polym 1982;33:619-23.

[36] Joanny JF, Castelnovo. Polyelectrolyte adsorption and multiplayer formation. Multilayer Thin Films. Weinheim: Wiley-VCH; 2002. p. 87-97.
[37] Lal N, Dubey J, Gaur P, Verma N, Verma A. Chitosan based in situ forming polyelectrolyte complexes: a potential sustained drug delivery polymeric carrier for high dose drugs. Mater Sci Eng C Mater Biol Appl 2017;79:491-8.

[38] Shiratori SS, Rubner MF. pH-Dependent thickness behavior of sequentially adsorbed layers of weak polyelectrolytes. Macromol 2000;33:4213-9.

[39] Bilensoy E, Rouf MA, Imran V, Murat S, Hincal AA. Mucoadhesive thermosensitive prolonged release vaginal gel for clotrimazole. AAPS PharmSciTech 2006:7-38.

[40] Sato H, Maeda M, Nakajima A. Mechanochemistry and permeability of polyelectrolyte complex membranes composed of poly (vinyl alcohol) derivatives. J Appl Polym Sci 1979;23:1759-1767/.

[41] Dainiak MB, Izumrudov VA, Muronetz VI, Galaev IY, Mattiasson B. Affinity precipitation of monoclonal antibodies by nonstoichiometric polyelectrolyte complexes. Bioseparation 1998;7:231-40.

[42] Webster L, Huglin MB, Robb ID. Complex formation between polyelectrolytes in dilute aqueous solution. Polymer 1997;38:1373-80.

[43] Kim B, Peppas NA. Analysis of molecular interactions in poly (methacrylic acid-g-ethylene glycol) hydrogels. Polym 2003; 44:3701-7.

[44] Xavier C, Jean-Francois J. Adsorption of polyelectrolyte solutions on surface: a Debye-Huckel theory. J Phys II France 1996;6:1669-86.

[45] Kokufuta E. Colloid titration behavior of poly(ethyleneimine). Macromolecules 1979;12:350.

[46] Sachiro K, Taguchi T, Hirofumi S, Tanaka J, Tateishi T. Injectable in situ forming Srug delivery systems for cancer chemotherapy using a novel tissue adhesive: characterization and in vitro evaluation. Eur J Pharm Biopharm 2007;295: 183-90.

[47] Lambert WJ, Peck KD. Development of an in situ forming biodegradable poly-lactide-co-glycoside system for the controlled release of proteins. J Contr Release 1995;33: 189-95.

[48] Chen S, Jagdish S. Controlled delivery of testosterone from smart polymer solution based systems : In vitro evaluation. Int J Pharm 2005;295:183-90.

[49] Haguland BO, RajashreeJ Kenneth JH. An in situ gelling system for parenteral delivery. J Control release 1996;41: 229-35.

[50] Nejat K, Eglimez Yong S, Jong Michael S, Sabel Jules S, Mathiowitz Edith, RichardB. Bankert et al, Biodegradable microspheres : induction of tumor regression and potent antitumor immunity. July 2000.

[51] Wataru K, YasuhiroK, Miyazaki S, Attwood D. In situ gelling pectin formulations for oral sustained delivery of paracetamol and ambroxol Drug develop. Ind Pharm 2004;30:593-9.

[52] Parekh H, Jivani R, Jivani N, Patel L, Makwana A, Sameja K. Novel insitu polymeric drug delivery system: a review. JDDT 2012;2(5).

[53] Miyazaki S, Suzuki S, Kawasaki N, Endo K, Takashi A, Attwood D. In situ gelling xyloglucan formulation for sustained release ocular delivery of pilocarpine hydrochloride. Ind J Pharm 2001;229:29-36.

[54] Miyazaki S, Suiha F, Kawasaki N. Thermally reversible xyloglucan gels for rectal drug delivery. J control Rel 1998;56: 75-83.

[55] Bilensoy E, Rouf MA, Imran V, Murat S, Hincal AA. Mucoadhesive thermosensitive prolonged release vaginal gel for clotrimazole. AAPS PharmSciTech 2006:7-38.

[56] Cao S, Ren X, Zhang Q, Chen E, Xu F, Chen J, et al. In situ gel based on gellan gum as new carrier for nasal administration of mometasone furoate. Int J Pharm 2009;365:109-15.

[57] Meka Venkata S, Manprit KG Sing, Pichika Mallikarjuna R, Nali Srinivasa R, Kolapalli Venkata RM Kesharwani Prashant. A comprehensive review on polyelectrolyte complexes. Drug Discov Today 2017;22(11): 1697-706. 
[58] Zhang X, Jackson J, Wong W, Min W, Cruz T, Hunter WL, et al. Development of biodegradable polymeric paste formulation for taxol: an in vivo and in vitro study. Int J Pharm 1996;137:199-208.

[59] Dardanoo SK, Oktaba AM, Hunter W, Min W, Cruz T, Burt HM. Release of taxol from polycaprolactone pastes : effect of water soluble additives. J Contr Release 1997;44: 87-94.
[60] Sawhney AS, Pathak CP, Rensberg JJV, Dunn RC, Hubbell JA. Optimization of photopolymerized bio-erodible hydrogel properties for adhesion prevention. J Biomed Mater Res 1994;21:11-23.

[61] Wu J, Wei W, Wang LY, Su ZG, Ma G. A thermosensitive hydrogel based on quaternized chitosan and poly (ethylene glycol) for nasal delivery system. Biomaterials 2007;28: 2220-32. 